\title{
Characterization of severity in fires that occurred in 2015 at the Chapada Diamantina National Park
} Sarah Moura Batista dos Santos ${ }^{1}$, António Bento-Gonçalves ${ }^{1}$, Washington de Jesus Sant'Anna da
Franca Rocha ${ }^{2}$, Gustavo Macêdo de Mello Baptista ${ }^{3}$, Cândida Caroline Souza de Santana Leite ${ }^{4}$

\author{
${ }^{1}$ CEGOT, Universidade do Minho, Guimarães, Portugal \\ ${ }^{2}$ PPGM, Universidade Estadual de Feira de Santana, Feira de Santana, Brasil \\ ${ }^{3}$ Instituto de Geociências, Universidade de Brasília, Brasília, Brasil \\ ${ }^{4}$ Instituto Nacional de Pesquisas Espaciais, São José dos Campos, Brasil \\ *e-mail: saamoura@gmail.com
}

\begin{abstract}
The Chapada Diamantina National Park (PNCD) is an integral protection unit, in which the rupestrian field vegetation prevails, a savanna type, which suffers recurrent fires. For the management of this environment, it is essential to analyze the severity, which can be defined as the magnitude of the change caused in the ecosystem by fire, due to the fire consuming the vegetation leaving the soil bare. Remote Sensing provides feasible approaches to describe fire patterns in different ecosystems, considering that satellite images are often used to outline fire perimeters and characterize the degree of severity. This study aims to assess the degree of fire severity that occurred at the PNDC in 2015, using the dNBR and RdNBR spectral indices. For the evaluation of post-fire effects for the selected areas, images of the Operational Land Imager (OLI) sensor were used onboard the Landsat-8 satellite. Four images of the OLI sensor were chosen in 2015, the pre-fire image of 28 August and the post-fire images of 25 September, 14 December and 30 December. For the pre-processing step the digital numbers were scaled to radiance values and after the conversion the images were corrected atmospheric, the method used for the atmospheric correction was FLAASH. The data obtained were pre-processed and properly prepared for the calculation of spectral indices and the results were classified according to the severity levels indicated by Key and Benson (2006) For the three analyzed fires, the dNBR index identified about $50 \%$ of the burned areas for the class Moderate low severity, with values between +270 to +439 , for the RdNBR index, approximately $80 \%$ of the areas burned for the high severity class was identified, with values between +660 to +1300 . It is concluded that the use of the multitemporal index dNBR and the relative index RdNBR are important tools for the classification of the burned area in the study area, as well as, supporting the development of actions aimed at fire prevention in the PNCD area considering the degrees of severity already experienced in that environment.
\end{abstract}

Keywords: vegetation fire, digital image processing, Landsat-8 sensor OLI, índice espectral 